\title{
Morphological study of the hard palate in the Egyptian goats (Capra hircus); A scanning electron microscopic study
}

\author{
Mohamed A. A. MAHDY ${ }^{\text {a, b, }{ }^{*}, \text { Kamal E. H. ABDALLAH }}{ }^{c}$, Salma A. MOHAMED ${ }^{\text {a }}$ \\ ${ }^{\text {a }}$ Department of Anatomy and Embryology, Faculty of Veterinary Medicine, South Valley University, Qena, Egypt \\ ${ }^{\mathrm{b}}$ Department of Anatomy and Physiology, University of Pretoria, Onderstepoort, South Africa. \\ ${ }^{c}$ Department of Anatomy and Histology, Faculty of Veterinary Medicine, Assiut University, Assiut, Egypt
}

Running title: Morphology of goat's hard palate

* Corresponding author: Mohamed A. A. MAHDY

Department of Anatomy and Physiology, University of Pretoria, Onderstepoort, 0110, South Africa.

Tel: +27 (0)81276 $5799 \quad$ Fax: +27(0)12 5298320

E.mail: $\underline{\text { m mahdi@vet.svu.edu.eg }}$ 


\begin{abstract}
:
The aim of the present study is to investigate the morphology of the goat hard palate by light and scanning electron microscopy (SEM), in addition to gross and morphometric analysis. A total of twelve goat heads, from normal adult and apparently healthy goats of both sexes, were collected from local slaughterhouses in Qena province, Egypt. Samples were subjected to gross examination, morphometric analysis, light microscopy, and scanning electron microscopy. The hard palate in the goats was long and could be divided into a rostral narrow part and a caudal wide part with about 12-15 transverse palatine ridges from which the rostral palatine ridges were serrated on their free caudal edges. The dental pad replaced the upper incisors, its caudal border had a serrated appearance. At higher magnification, SEM of the epithelial surface of the palatine rugae and incisive papilla revealed a variety in the shape of the microplicae and the pattern of the micropits. These adaptations of the goat's hard palate might increase its efficiency during ingestion and mastication of coarse roughages and in directing the food backwards. To our knowledge, this is the first study showed the detailed anatomical description of the hard palate of the goat with SEM.
\end{abstract}

Keywords: Dental pad, goat, hard palate, morphometry, palatine ridges, SEM 


\subsection{INTRODUCTION}

The goat is the first animal to be domesticated, about 8000 years ago (Boyazoglu et al., 2005). The domestic goat is distributed worldwide with about $95 \%$ of the world's goat population is present in the developing countries. Goat is considered as an important economic source of meat, milk and fiber production (Dhanda et al., 2003). Moreover, their special characteristics, such as small body size, low metabolic requirements, ability to reduce metabolism, efficient digestion of high-fiber forage, and ability to withstand dehydration, enable them to survive in harsh environments (Silanikove, 2000). Recently, there is an increased demand for goat products in both developing and developed countries (Sahlu \& Goetsch, 2005).

Goats are classified as intermediate feeders between grazers and browsers: they can alter their feeding strategy, as a morphological adaptation to seasonal shift in forage quality (Hofmann, 1989). They usually feed green grasses and browse when preferred food availability decreases (Dumont et al., 1995). The physiological mechanisms and feeding behavior of animal are two important factors which directly affect the productive performance of the animal (Silva et al., 2016). Therefore, studying the anatomical and physiological characteristics of the oral cavity in goats provides better understanding of their feeding habits and diets.

The hard palate is an important part of the oral cavity and plays a unique role during food prehension and mastication as it forms a hard surface opposite to the tongue so the tongue can press food against it (Akers \& Denbow, 2013). Encarnacion et al. (2015) compared the hard palate of goat and sheep morphologically and use palatine prints as a method of identification. However, the available information about the hard palate morphology in the goat in veterinary anatomy textbooks are scarce (Nickel et al., 1979; KöNig \& Liebich, 2007; Dyce et al., 2010). Moreover, there is no study showing the detailed morphology of the hard palate in goat. 
Therefore, the aim of the present study is to investigate the hard palate of the goat using gross morphology, morphometry, histological structure, and scanning electron microscopy (SEM). The information provided in this study should be useful in describing adaptation of the hard palate in feeding and in comparative anatomy with other breeds of goats on one hand, and other ruminants on the other hand.

The present study showed that the hard palate of the goat was divided into a rostral narrow part and a caudal wide part with about 12-15 transverse palatine ridges from which the rostral palatine ridges were serrated on their free caudal edges. The dental pad replaced the upper incisors, its caudal border has a serrated appearance. At higher magnification, SEM of the epithelial surface of palatine rugae and incisive papilla revealed a variety in the shape of the microplicae and the pattern of the micropits. These adaptations of the goat's hard palate might increase its efficiency during food mastication and in directing the food backwards. To our knowledge, this is the first study showed the detailed anatomical description of the hard palate of the goat with SEM. 


\subsection{MATERIALS AND METHODS}

\subsubsection{Sample collection}

A total of twelve goat heads, from normal adult and apparently healthy goats of both sexes, were collected directly after animal slaughtering from local slaughterhouses in Qena province, Egypt following the guidelines of the Institutional Ethical Committee.

\subsubsection{Gross examination}

To expose the hard palate, the upper and lower jaws were separated through the temporomandibular articulation. The samples were washed with saline and fixed in $10 \%$ neutral buffered formalin (NBF) for gross examination and morphometry.

\subsubsection{Morphometric analysis}

For morphometric analysis, the lengths and widths of different parts of the hard palate were measured using Digital Vernier Caliper (Shenzhen Liance Electronic Technology Co., Ltd., Shenzhen- China). Moreover, the dimensions of the dental pad and incisive papilla were recorded. Data were expressed as Mean $\pm \mathrm{SD}$.

\subsubsection{Light Microscopy}

Samples were fixed in $10 \%$ NBF for $24 \mathrm{~h}$, dehydrated in ascending grades of alcohol and embedded in paraffin wax. Serial sections (5 $\mu \mathrm{m}$ in thickness) were obtained and stained with Mayer's Hematoxylin and Eosin (HE) stain.

\subsubsection{Scanning Electron Microscopy (SEM)}

Specimens were prepared according to the previous study (Mahdy et al., 2013). Briefly, samples were fixed in $4 \%$ glutaraldehyde for $24 \mathrm{~h}$, then post fixed in $2 \%$ buffered osmium tetroxide. The

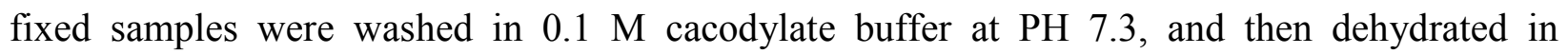


ascending grades of ethanol, critical point-dried in liquid carbon dioxide, and mounted on metal stubs. Specimens were coated with gold palladium in sputtering device, then examined and photographed using scanning electron microscope (JSM-4500 LV, JEOL Ltd., Japan) operated at $20 \mathrm{KV}$. 


\subsection{RESULTS}

\subsubsection{Hard palate}

\subsubsection{Gross morphology}

The hard palate (Palatum durum) of the Egyptian goat was elongated in shape, about $96.9 \pm 3.3$ $\mathrm{mm}$ long, it was narrow rostrally and wide caudally. It could be divided according to its width into a rostral narrow part and a caudal wide part, they formed $37.7 \%$ and $62.3 \%$ from the total length of the hard palate, respectively (Table 1). The narrow part was nearly uniform in width, it measured about $19.0 \pm 1.1 \mathrm{~mm}$ wide. While the wide part began abruptly at the level of the second upper premolar tooth, then it gradually increased in width caudally to become about 34.4 $\pm 2.1 \mathrm{~mm}$ wide at level of last molar tooth.

The palatine raphe (Raphe palati) was in the form of a prominent groove. It extended from the dental pad rostrally till the level of the last upper premolar tooth, then it continued caudally by a shallow groove which terminated about $8.9 \pm 0.6 \mathrm{~mm}$ rostral to the caudal end of the hard palate. The palatine raphe measured about $87.9 \pm 3.6 \mathrm{~mm}$ long.

There were about 12-15 transversely arranged palatine ridges (Rugae palatinae) on either side of the palatine raphe, they extended caudally up to the level between the third and fourth upper premolar teeth. Therefore, the palatine ridges occupied the entire narrow part and the front portion of the wide part, while the caudal portion of the wide part was smooth (Fig.1A). According to the distribution of palatine ridges, the hard palate could be divided into rough ridged part and smooth part, they formed about 53\% and $47 \%$ from the total length of the hard palate, respectively (Table 1). The palatine ridges were closely arranged in the narrow part of the hard palate and more or less separated in the wide part of the palate, therefore, the palatine ridges 
Table 1: Morphometric analysis of the hard palate

\begin{tabular}{lc}
\hline Dimensions of the hard palate & Mean \pm SD (mm) \\
\hline -Total length of hard palate & $96.9 \pm 3.3$ \\
- Length of the $\quad$ - Narrow part & $36.5 \pm 1.8$ \\
- Wide part & $60.4 \pm 1.9$ \\
- Rough part & $51.3 \pm 2.3$ \\
& \\
- Smooth part & $45.5 \pm 2.6$ \\
\hline
\end{tabular}

- Width of the narrow part

$19.0 \pm 1.1$

- Width of the wide part at

$\begin{array}{lr}-2^{\text {nd }} \text { premolar tooth } & 23.9 \pm 1.3 \\ -1^{\text {st }} \text { molar tooth } & 30.6 \pm 3.0 \\ \text { - Last molar tooth } & 34.4 \pm 2.1\end{array}$

- Total length of palatine raphe

$87.9 \pm 3.6$

- Length of the deep part

$55.0 \pm 3.4$

- Length of shallow part

$32.9 \pm 2.7$ 
Fig. 1
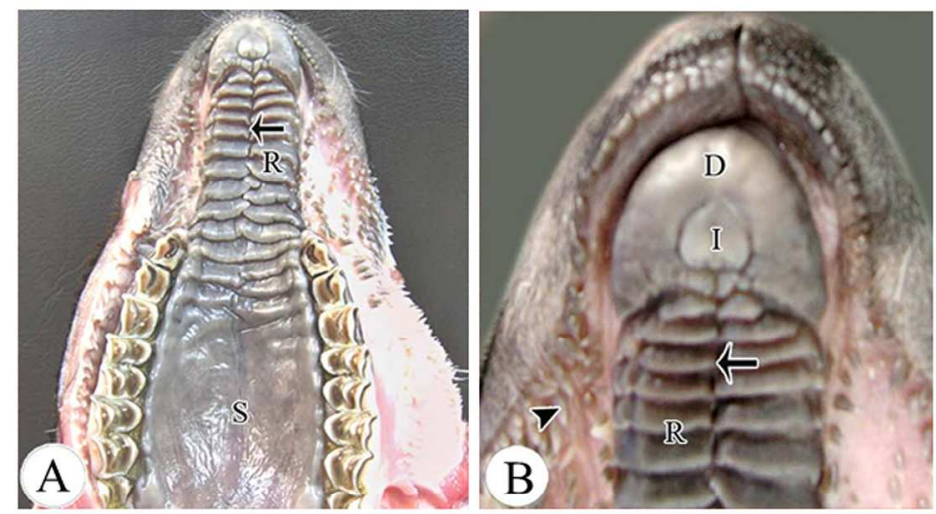

Figure 1. Gross anatomical description of the hard palate of the goat showing [A] the hard palate divided into rostral rough part with palatine raphe (arrow) and rugae (R) and caudal smooth part (S). [B] The rostral part of hard palate showing dental pad (D), incisive papilla (I), palatine raphe (arrow), palatine ridges $(R)$ and labial papillae (arrow head).

$275 \times 397 \mathrm{~mm}(300 \times 300 \mathrm{DPI})$ 
were not equally spaced. Moreover, the ridges of the wide part were situated in alternative manner with a transverse direction.

\subsubsection{SEM examination}

The SEM showed that the rostral palatine ridges were serrated laterally on the free caudal edges. The surface of the ridges was covered by keratinized epithelium. Desquamation and sloughing of the epithelial cells were apparent in different degrees due to the slop of various areas of the palatine ridges (Fig. 2A, 2B).

\subsubsection{Histological examination}

Histologically, the epithelium of the rough part of the hard palate, which contained the palatine ridges, was composed of keratinized stratified squamous epithelium (Fig. 3A). The stratum corneum of the hard palate was especially thick. The epithelium was indented by numerous long and short connective tissue papillae of the lamina propria. The submucosa contained abundant adipose tissue, venous plexuses, and cavernous tissue supported by collagenous bundles which run in different directions.

\subsubsection{Dental pad}

\subsubsection{Gross morphology}

The dental pad (Pulvinus dentalis), a thickening replaced the upper incisors, was represented by a crescentic thick plate (Fig. 1B) that was attached to the underlying body of the incisive bone. It measured about $24.4 \mathrm{~mm}$ long (from its rostral end to its caudal end) and $19.6 \mathrm{~mm}$ wide (from side to side at the caudal end) (Table. 2). Caudally, the dental pad terminated about 6.0 mm caudal to the level of the corner incisor tooth. Macroscopically, the outer convex border of the dental pad was smooth. However, its caudal (inner) concave border had a serrated appearance 
Fig. 2

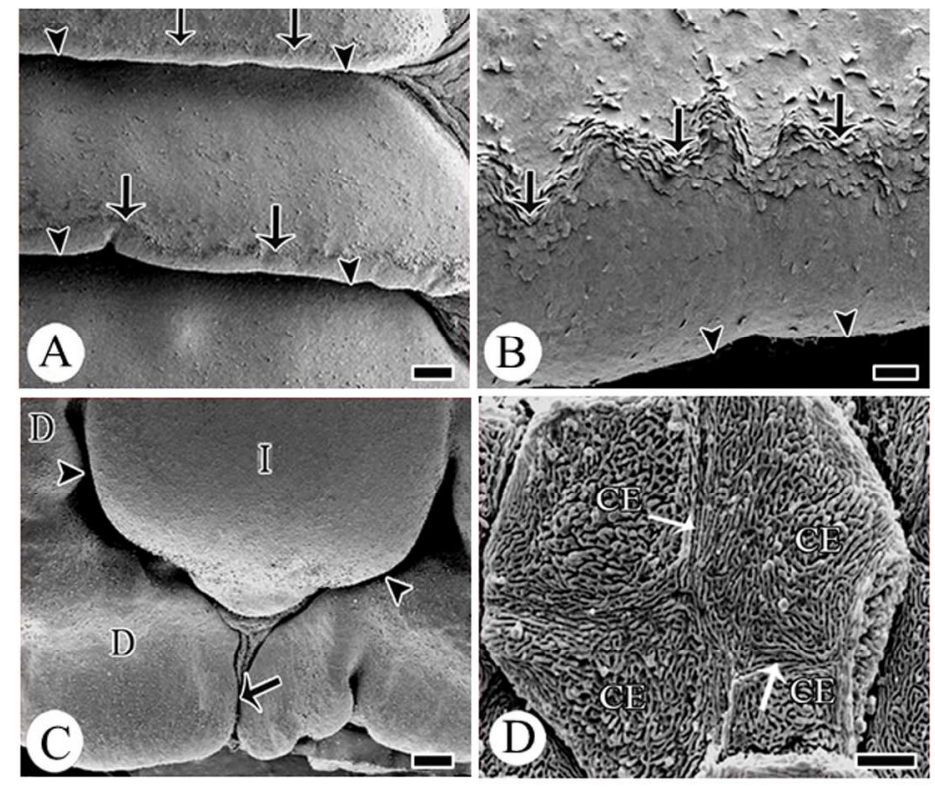

Figure 2. Scanning electron micrographs of the hard palate showing $[A]$ transverse rugae of hard palate. Note the area of highest degree of desquamation and sloughing (arrows) was located near the caudal border (arrow heads), scale bar $=500 \mu \mathrm{m}$. [B] Higher magnification of the previous picture with area of desquamated and sloughed epithelial cells (arrows) near the caudal edge (arrow heads) of the palatine ridge, scale bar $=80 \mu \mathrm{m}$. [C] The incisive papilla (I) showing caudolaterally situated C-shaped groove (arrow heads) separated the papilla from the dental pad (D) and continues caudally (arrow) with the palatine raphe, scale bar $=500 \mu \mathrm{m}$. [D] Microplicae of the incisive papilla. Note hexagonal epithelial cell divided into 5 cellulae (CE) by secondary septulae (arrows), scale bar $=4 \mu \mathrm{m}$. 
Table 2: Morphometric analysis of the dental pad

Dimensions of the dental pad

- Length (rostral end to caudal end)

- Width (from side to side) at caudal end

- Rostrocaudal diameter (in the middle)

- Distance between caudal end and corner incisor

- Diameter of incisive papilla
Mean \pm SD (mm)

$24.36 \pm 1.28$

$19.59 \pm 0.76$

$14.35 \pm 0.76$

$6.01 \pm 1.37$

$5.41 \pm 0.38$ 
due to the presence of caudally directed papillae. The caudal part of the ventral aspect of the dental pad was occupied centrally by the incisive papilla.

The incisive papilla (Papilla incisiva) was nearly rounded prominence occupying the center of the caudal part of the ventral surface of the dental pad. It measured about $5.4 \mathrm{~mm}$ in diameter. The incisive papilla continued rostrally with the dental pad, but it was margined on both sides and on its caudal part by a groove. The caudal aspect of the incisive papilla was separated from the first row of palatine ridges by caudally directed papillae which form the caudal border of the dental pad.

\subsubsection{SEM examination}

The SEM showed that the incisive papilla had a central projection caudally opposite to the rostral end of the palatine raphe (Fig. 2C). It was separated from the surrounding dental pad laterally and caudally by a C-shaped groove with the concavity of this groove was directed rostrally. Caudally, this groove separated the incisive papilla from the caudal aspect of the dental pad. The C-shaped groove was wider laterally than caudally. The caudal concave border of the dental pad showed 3-4 caudally directed papillae on each side, of them the medial papillae were larger than the lateral ones. The most medial papilla of each side was separated from that of the opposite side by a median groove through which the $\mathrm{C}$-shaped groove of the incisive papilla continued caudally with the groove of the median palatine raphe.

\subsubsection{Histological examination}

Histologically, the incisive papillae and dental pad were lined by highly keratinized stratified squamous epithelium (Fig. 3B) which extended to line the groove separating the two structures. The stratum corneum of the incisive papillae was relatively thicker than that of the dental pad. Connective tissue papillae of different sizes indent the epithelium, these papillae were numerous 


\section{Fig. 3}

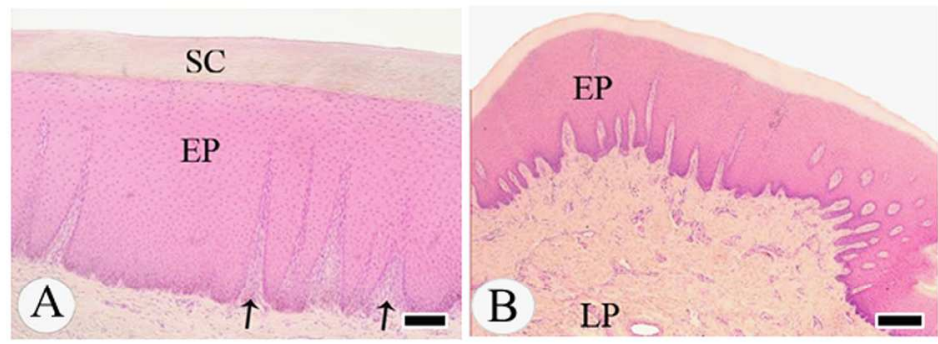

Figure 3. Light micrographs showing [A] hard palate with keratinized stratified squamous epithelium (EP) indented by long connective tissue papillae (arrows) and thick stratum corneum (SC), HE Stain, scale bar = $200 \mu \mathrm{m}$. [B] Dental pad with keratinized stratified squamous epithelium (EP) and lamina propria, HE Stain, scale bar $=500 \mu \mathrm{m}$.

$275 \times 397 \mathrm{~mm}(300 \times 300 \mathrm{DPI})$ 
at the groove than at the incisive papilla and dental pad. The lamina propria was composed of highly vascularized dense connective tissue. Cartilaginous plate of hyaline type was demonstrated under the dental pad.

\subsubsection{Microplicae system of the hard palate}

The epithelium of palatine ridges showed a dense arrangement of microplicae system which consisted of numerous branched and interconnecting microridges surrounding micropits. The intercellular borders were thin and form irregular polygonal cell surface outlines. The micropits of the rugae were large in size with different shapes, consequently the free surface of their epithelial cells had a honeycomb appearance.

The incisive papilla (Fig. 2D) showed a complex pattern of microplicae which were extensively branched and interwoven to form web-like patterns. The intercellular border was prominent and clearly distinct demarcating typical hexagonal cells, in addition, some of these cells were polygonal in outlines. The surface of each epithelial cell was divided into $4-5$ cellulae by secondary septulae extending from the intercellular borders. The density of the microplicae was more in the periphery of the cell than in the center. The micropits were generally large but wider in the center of the cell than in the periphery. 


\subsection{DISCUSSION}

The present study demonstrated the morphology of the hard palate of the Egyptian goat by using gross examination, morphometry, SEM, and light microscopy.

\subsubsection{Hard palate:}

The hard palate in the examined goats could be divided according to its width into a narrow rostral part, nearly uniform in width, and a caudal wide part, began abruptly at the level of the second upper premolar tooth and then it gradually increased in width caudally. These results are, to some extent, in agreement with the previous records reported by Nickel et al. (1979) who reported that the goat's hard palate is uniform in width and widens abruptly caudal to the level of the first cheek tooth. In contrast, in Bakerwali goats, the hard palate is narrow at the tip, more narrower at its middle part and broader at its terminal part (Sarma et al., 2012). Moreover, Encarnacion et al. (2015) showed that the hard palate of sheep and goat is narrowest at the middle part and widest at the caudal part.

The current morphometric results showed that the length of hard palate of the Egyptian goat was about $96.9 \mathrm{~mm}$ long. Similar results were reported in Rasquera White goat (Parés-Casanova, 2014). In contrast, Red Sokoto goat showed longer hard palate, $11.02 \mathrm{~mm}$ long (Olopade \& Onwuka, 2008). The difference in the length of the hard palate between the Egyptian goat and the Red Sokoto goat might be related to the size of the goats. Encarnacion et al. (2015) suggested a positive relationship between the length of the hard palate and the time for grinding of coarse feed inside the mouth before reaching caudal part of oral cavity. This suggestion is supported by the results of Domingue et al. (1991) who reported that goats spend more time during food prehension than sheep which increases their efficiency in breaking down of large particles during 
prehension compared to sheep. Taken together, the relatively long hard palate of the goat allows efficient grinding of coarse roughages before swallowing.

Our morphometric results showed that the rough part of the hard palate, containing ridges, was about $53 \%$ of the total length of the hard palate. In contrast to our findings, Sarma et al. (2012) showed that the palatine ridges cover the anterior two thirds of the hard palate in Bakerwali goats. On the other hand, the number of palatine ridges in the current study was about 12-15 ridges on either side of the median raphe. This is in agreement with the findings of Halata et al. (1999) who showed the presence of 12-14 pairs of palatine ridges. Our results are in contrast to those previously reported by Sarma et al. (2012) and Encarnacion et al. (2015) who reported fewer number of palatine ridges in goats and in goats and sheep, 10-11 and 10 ridges, respectively. Encarnacion et al. (2015) excluded branched and fused ridges from counting which might explain the difference in the reported number of palatine ridges. The palatine ridges help the tongue during food prehension and mastication (Nickel et al., 1979). Moreover, they assist in retaining food within the mouth (Smith, 1990) and guide the food backward to oropharynx during swallowing (KöNig \& Liebich, 2007). Encarnacion et al. (2015) suggested that the presence of larger number of palatine ridges together with their caudally directed free borders increase the efficiency of the hard palate in directing the food backwards.

\subsubsection{Dental pad}

The present study showed that the dental pad in the goat had the shape of a crescentic thick plate with a serrated caudal concave border. The dental pad replaces the upper incisors and canines in goats (Halata et al., 1999). The dental pad is formed of dense connective tissue and covered by a thick cornified epithelium (Sreeranjini et al., 2010). It acts as a counterpart to the lower incisors 
in grazing (Dyce et al., 2010; Sreeranjini et al., 2010). Goat pulls off grass and leaves by pressing them between the tongue and the palate because it lacks upper incisors (Halata et al., 1999). In agreement to our findings, Sreeranjini et al. (2010) showed the presence of small caudally directed papillae on the caudal border of dental pad in sambar deer which give it a serrated appearance. In contrast to our findings, Encarnacion et al. (2015) showed that the caudal border of dental pad in sheep and goat is smooth and non-papillated. It is suggested that the welldeveloped dental pad might help goats during ingestion of coarse roughages and pulling off grasses.

\subsubsection{Incisive papilla}

The current study showed that the incisive papilla was nearly rounded prominence occupied the center of the caudal part of the dental pad. The incisive papilla is half-moon-shaped in Bakerwali goat (Sarma et al., 2012) and diamond-shaped in sambar deer (Sreeranjini et al., 2010). In agreement to our findings, Sreeranjini et al. (2010) showed that the incisive papilla is located between the dental pad and the first pair of ridges. The incisive papilla according to our findings was separated from the first row of palatine ridges by caudally directed papillae which form the caudal border of the dental pad. On the other hand, the incisive papilla was separated from the dental pad laterally and caudally by a C-shaped groove. This groove contains the palatine openings of the incisive duct (Nickel et al., 1979). Furthermore, the incisive papilla of the goat is rich with free nerve endings and specific mechanoreceptors which suggests an important role in monitoring the mechanical properties of the ingested food before entering the mouth (Halata et al., 1999). 


\subsubsection{Histology}

Our results showed that the mucous membrane of the hard palate and incisive papilla were lined by highly keratinized stratified squamous epithelium. This result was consistent with that reported in sheep and goat by Encarnacion et al. (2015), they added that the presence of thick and highly keratinized epithelium in the hard palate provides a protection to the underlying layers of mucosa from damaging by abrasions from ingested food. The masticatory mucosa of the hard palate is subjected to heavy mechanical loads, therefore, the horny epithelium modifies to adapt these mechanical loads (Halata et al., 1999). Consequently, it was worthy to clarify here that the desquamation and sloughing of the epithelial cells of the palatine rugae, which were shown in the present results, might be due to the mechanical loads on these rugae during the mastication and swallowing of the food.

\subsubsection{Microplicae System}

At higher magnification, the surface of the palatine ridges, dental pad, and incisive papilla showed winding ridge-like folds, microplicae. These parts of the hard palate consist of stratified squamous epithelium and are subjected to mechanical stress through rubbing against other surfaces of foreign objects during food prehension and mastication, therefore, microplicae provide mechanical protection by decreasing the frictional resistance between the opposing surfaces and reduction of the surface area of contact (Andrews, 1976; Asikainen et al., 2015).

The microplicae of the palatine ridges had a honeycomb appearance which appear similar to the microplicae that previously reported on the surface of goat sublingual caruncle (Mahdy et al., 2013). Microplicae with honeycomb appearance is characteristic to keratinized epithelial cells (Asikainen et al., 2015). However, the microplicae of the incisive papilla had a different shape compared to that in palatine ridges. In this respect, it was reported that different parts of oral 
epithelial cells have characteristic features of microplicae system which enable easy identification of these parts (Grossman, 1987).

\subsection{CONCLUSION}

In conclusion, the present study provided a detailed anatomical description of the hard palate of the Egyptian goat (Capra hircus) using gross examination, morphometry, SEM, and histological examination for the first time. The goat's hard palate had specific adaptations which might increase its efficiency during ingestion and mastication of coarse roughages and in directing the food backwards. On the other hand, this study will help to compare hard palate of the goat with that of other ruminant animals, in addition, it might be as a reference guide for the interpretation of normal and pathological conditions. 


\section{ACKNOWLEDGEMENTS}

The authors acknowledge South Valley University for financial support of this study and University of Pretoria for providing Postdoctoral Fellowship to the first author.

\section{CONFLICT OF INTEREST}

The authors declare that they have no conflict of interest. 


\section{REFERENCES}

Akers, R. M., Denbow, D. M. 2013. Digestive system. Anatomy and physiology of domestic animals. 2nd ed. Iowa, West Sussex, Oxford: Blackwell Publishing.

Andrews, P. M. 1976. Microplicae: characteristic ridge-like folds of the plasmalemma. J Cell Biol, 68, 420-429.

Asikainen, P., Sirvio, E., Mikkonen, J. J., Singh, S. P., Schulten, E. A., ten Bruggenkate, C. M., et al. 2015. Microplicae-specialized surface structure of epithelial cells of wet-surfaced oral mucosa. Ultrastruct Pathol, 39, 299-305.

Boyazoglu, J., Hatziminaoglou, I., Morand-Fehr, P. 2005. The role of the goat in society: Past, present and perspectives for the future. Small Rumin Res, 60, 13-23.

Dhanda, J. S., Taylor, D. G., Murray, P. J., Pegg, R. B., Shand, P. J. 2003. Goat meat production: Present status and future possibilities Asian-Aust. J. Anim. Sci. , 16, 1842-1852.

Domingue, B. M., Dellow, D. W., Barry, T. N. 1991. The efficiency of chewing during eating and ruminating in goats and sheep. Br J Nutr, 65, 355-363.

Dumont, B., Meuret, M., Prud'hon, M. 1995. Direct observation of biting for studying grazing behavior of goats and llamas on garrigue rangelands. Small Rum Res, 16, 27-35.

Dyce, K. M., Sack, W. O., Wensing, C. J. G. 2010. Textbook of veterinary anatomy, St. Louis, Missouri, Saunders/Elsevier.

Encarnacion, J. M. L., Maala, C. P., Ducusin, R. J. T. 2015. Comparative gross and microscopic anatomy of the hard palate and palatine printing in goat (Capra hircus L.) and Sheep (Ovis aries L.). Philipp J Vet Med, 52, 71-82.

Grossman, E. S. 1987. A histometric/scanning electron microscope study of normal and loaded oral epithelium of the vervet monkey. J Anat, 154, 81-90. 
Halata, Z., Cooper, Y. B., Baumann, I. K., Schwegmann, C., Friedman, M. R. 1999. Sensory nerve endings in the hard palate and papilla incisiva of the goat. Exp Brain Res, 129, 218 228.

Hofmann, R. R. 1989. Evolutionary steps of ecophysiological adaptation and diversification of ruminants: a comparative view of their digestive system. Oecologia, 78, 443-457.

König, H. E., Liebich, H.-G. 2007. Digestive system (apparatus digestorius). In: KöNig, H. E. \& Liebich, H.-G. (eds.) Veterinary anatomy of domestic mammals : textbook and colour atlas. 3 rd ed. Stuttgart; New York: Schattauer.

Mahdy, M. A. A., Abdalla, K. E. H., Mohamed, S. A. 2013. Anatomical Studies on the Sublingual Caruncles of the Goat. Advances in Zoology and Botany, 1, 30-33.

Nickel, R., Schummer, A., Seiferle, E., Sack, W. 1979. Digestive System. The Viscera of the Domestic Mammals. Springer New York.

Olopade, J. O., Onwuka, S. K. 2008. A craniometric analysis of the skull of the Red Sokoto (Maradi) goat (Capra Hircus). Eur. J. Anat., 12, 57-62.

Parés-Casanova, P. M. 2014. Osteometric study of the Rasquera White goat. Journal of Applied Animal Research, 42, 177-185.

Sahlu, T., Goetsch, A. L. 2005. A foresight on goat research. Small Rum Res, 60, 7-12.

Sarma, K., Suri, S., Devi, J., Doley, P. J. 2012. Morphological studies on the mouth cavity of Bakerwali goat (Capra hircus) of Jammu Region. Ind J Vet Anat, 24, 20-21.

Silanikove, N. 2000. The physiological basis of adaptation in goats to harsh environments. Small Rum Res, 35, 181-193. 
Silva, T. M., Oliveira, R. L., do Nascimento Júnior, N. G., de Pellegrini, C. B., Trajano, J. d. S., Rocha, T. C., et al. 2016. Ingestive behavior and physiological parameters of goats fed diets containing peanut cake from biodiesel. Trop Anim Health Prod, 48, 59-66.

Smith, B. J. 1990. Canine anatomy, Philadelphia, Baltimore, New York, London, Lippincott Williams \& Wilkins.

Sreeranjini, A. R., Rajani, C. V., Ashok, N. 2010. Gross anatomical studies on the hard palate, tongue and buccal floor in sambar deer (Cervus unicolor). TNJVAS, 6, 151-156. 